\title{
Injection moulding of long glass fibre reinforced poly(ethylene terephtalate): Influence of carbon black and nucleating agents on impact properties
}

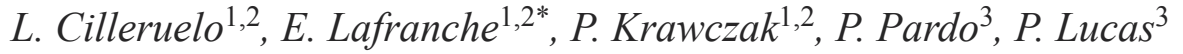 \\ ${ }^{1}$ Université Lille Nord de France, 59000 Lille, France \\ ${ }^{2}$ Ecole des Mines de Douai, Polymers and Composites Technology \& Mechanical Engineering Department, 941 rue \\ Charles Bourseul, BP 10838, 59508 Douai, France \\ ${ }^{3}$ OCV Reinforcements, 767 Quai des Allobroges, BP 929, 73009 Chambéry, France
}

Received 3 January 2012; accepted in revised form 16 March 2012

\begin{abstract}
This paper aims at highlighting the influence of different additives (carbon black and nucleating agents) on both the notched and unnotched Charpy impact properties of long glass fibre reinforced poly(ethylene terephtalate) injection mouldings. The relationship with the polymer matrix and composite microstructure modifications (variations of crystalline morphology and local fibre content) was investigated. Adding carbon black alone decreases the impact performances. This highly conductive additive actually increases the cooling rate, and therefore the fibre 'frettage' effect (higher internal stresses). It also acts as filler, which increases the material brittleness. The nucleating agents allow reducing the mould temperature, but their effect on the impact strength may be favourable or not depending on the processing temperatures. The addition of such additives induces perturbations of the polymer melt rheology in the mould cavity and of the cooling kinetics of the part, which both act on the fibre distribution during mould filling and on the degree of crystallinity of the composite parts.
\end{abstract}

Keywords: polymer composites, long fibre thermoplastics, mechanical properties, nucleating agent, carbon black

\section{Introduction}

Combining some advantages of short glass fibre reinforced thermoplastics (e.g. easy processing by injection moulding) and GMT (Glass Mat reinforced Thermoplastic) composites (e.g. continuous fibre), long glass fibre reinforced thermoplastics (LFT) are finding ever-growing applications due to their excellent short and long term mechanical performances compared to their challengers. For instance in the automotive industry, LFTs show a great potential for metal substitution in terms of both cost-effectiveness and vehicle lightening [1, 2]. The marketed LFT compounds were originally limited to polypropylene (PP) reinforcement and numerous studies are therefore available on this material (among others, an excellent paper series by Thomason and coworkers [3-9]). Other matrices are now also commercially available, such as polyamides (PA) 6 or 6-6 and polyesters (pol(ethylene terephtalate) (PET), poly(butylene terephtalate) (PBT)) among others. Unfortunately, the scientific literature is much more limited on PA 6-6 [10-16], and even more on PET [17] based LFTs.

Whatever is the forecasted industrial application, LFT-based solutions require in numerous cases a subtle balance between the short term mechanical properties and the durability, the mechanisms of brittleness and damage being in close relation with

\footnotetext{
${ }^{*}$ Corresponding author, e-mail: eric.lafranche@mines-douai.fr
} (c) BME-PT 
the loading velocity. Generally, the failure of chopped fibre composites is mainly governed by fibre breakage in case of long fibres, and by the deformation of the matrix and the fibre/matrix debonding in case of short fibres [18]. The literature shows [15, 18-22] that the impact strength of the LFT is strongly influenced by the fibre residual length, concentration, distribution and orientation in the part, as well as by factors depending on processing and testing conditions (impact speed, temperature, presence of notch in the sample, etc.), much more in the case of high loading speed (typically in the range of a couple of $\mathrm{m} \cdot \mathrm{s}^{-1}$ ) than in the case of low loading velocity (typically in the range of 1 to $100 \mathrm{~mm} \cdot \mathrm{min}^{-1}$ ).

Karger-Kocsis [19] reported a comparative analysis of notched Charpy impact behaviour of polypropylene (PP) reinforced with different long and short fibre contents. The ductility index $(\mathrm{DI}=$ crack growth energy/total breakage energy) increases with increasing fibre volume fraction of long fibres, whereas it quickly reaches a maximum and then drops in the case of short fibres. These trends were confirmed by Vu-Khanh and Denault [20]. These authors observed that the impact strength of chopped fibre polypropylene composites increases at lower temperatures and for parts reinforced with the longest fibres. Also, Thomason and Vlug [6] established the relationship existing between the fibre content and the impact strength of PP composites with different fibre lengths. The impact strength increases almost linearly with the fibre weight content and reaches an asymptote (plateau) when fibres are longer than $6 \mathrm{~mm}$. More recently, the same author reported that the notched impact strength is the highest when fibre contents are in the range $40-50 \mathrm{wt} \%$, whereas the maximum of the unnotched impact strength appears at a fibre content of about $30 \mathrm{wt} \%$ only [8]. The impact strength quickly drops above these limits. Moreover, as for the tensile or flexural strengths $[5,8,10$, $14,15]$ different authors evidenced that the residual fibre length and the fibre orientations influence the impact strength $[8,21]$.

In the case of PP reinforced with $50 \mathrm{wt} \%$ glass fibres having initial fibre length of $10 \mathrm{~mm}$ (reduced to $1.8-2.0 \mathrm{~mm}$ after injection moulding), Skourlis et al. [22] furthermore highlighted the influence of the thickness of the skin and core layers of the part, induced by the shear and fountain flows during processing. As the reinforcement effect is related to the fibre alignment along the flow direction, the processing parameters which favour the fibre orientation in the skin layer and the increase of its thickness (e.g. low mould temperature and low injection speed) lead to impact strength increase [22]. Cilleruelo et al. [17] confirmed that it is possible to optimise the impact strength of $30 \mathrm{wt} \%$ long fibre reinforced poly(ethylene terephtalate) (PET) by properly setting the two above-mentioned main influencing parameters, however at opposite setting levels compared to those recommended to optimise flexural properties [11, 15].

Beyond the factors mentioned previously, the incorporation of additives in the thermoplastic matrices (pigments/dyes, nucleating agents, etc.) which are likely to modify the structure of the composite (matrix morphology and fibre/matrix interphase), may also induce variations in mechanical performance, particularly in impact strength. Carbon black is the most used pigment in the plastics industry, particularly for automotive applications. Carbon black is available in the form of granules, fibres or powder. It is composed of crystalline agglomerated elements (micro-crystals). This ability to agglomerate induces the formation of a spatial network within the filled polymer that behaves as fibrous fillers. Its peculiar geometry modifies the polymer structure and causes a decrease in the material strength even at low concentrations [23]. It may also affect the polymer crystallisation acting as heterogeneous nucleating agent, and modifies the crystallisation kinetics and temperature.

Besides, nucleating agents (e.g. most commonly carboxylate or phosphate ester salts, and sorbitol acetals) are often added to semi-crystalline polymers such as PET [24-27] or PP [28, 29] in order to modify the crystallisation kinetics and mechanism (increase of the crystallisation rate, leading to a faster polymer solidification), consequently leading to injection moulding cycle time reduction. In particular, PET is characterised by a very slow crystallisation and nucleating agents are often added to control a more homogeneous structure through a uniform spherulite size more than to increase the degree of crystallinity of the polymer. The sodium salts usually used as nucleating agent do not act as nucleation centres themselves but interact with the PET molecules to give sodium terephtalate chains that are the effective nucleating species. These nucle- 
ophilic substitution chemical reactions induce a global molecular weight decrease of the polymer [24-26]. Sodium benzoate nucleating agent is wellknown to substantially increase the crystallization rate of poly(ethylene terephtalate) at higher temperature and to accelerate crystallization even more at lower temperature with an additional improvement of molecular mobility of PET chains, but the increase of crystallization rate is limited by the fact that sodium benzoate may be only partially soluble in PET matrix [26, 27]. The sodium 2,2'-methtylenebis(4,6-di-tert-butylphenyl)phosphate nucleating agent is usually used to increase the crystallization rate of polyolefins, polyamides and PET; it may induce smaller spherulites than sodium benzoate at higher crystallization temperature with shorter crystallization half time $[28,29]$. On the other hand, the nucleating agents strongly influence the crystalline zone between the fibre and the matrix. This zone is constituted by three areas the first one is the interface between the fibre and the transcrystalline phase of the polymer, the second one is the transcryslline homogeneous part influenced by the cooling rate, the fibre treatment, the free surface of the fibre or by the nucleating agents, and the third one is the interphase between the transcrystalline phase and the matrix [30].

As a consequence, the composites mechanical properties (e.g. strength, toughness, brittleness) may be strongly affected. In particular, smaller spherulites resulting from nucleating agents addition are likely to improve the impact strength of crystalline matrices [31-33]. However, to our better knowledge, the influence of carbon black and/or nucleating agents addition on impact properties has never been reported in the case of PET-based LFTs.

In this context, as long glass fibre/PET compounds were rarely studied, the optimisation of long glass fibre/poly(ethylene terephtalate) injection moulding still needs dedicated research efforts. The effect of injection moulding conditions and the existence of fibre segregation phenomena along the flow path and through the thickness were reported in a previous paper [17]. In the present paper, the influence of different additives (carbon black and nucleating agents) on the Charpy impact properties of long glass fibre/PET injection-mouldings is investigated. The relationship with the polymer matrix and composite microstructure modifications (variations of crystalline morphology and local fibre content) is highlighted.

\section{Experimental}

\subsection{Materials}

The material studied was a poly(ethylene terephtalate) (PET) reinforced by $30 \mathrm{wt} \%$ of $12.5 \mathrm{~mm}$ long glass fibres (LGF) having an $18 \mu \mathrm{m}$ diameter. It was obtained by diluting concentrated glass/PET commingled pellets (Twintex ${ }^{\circledR}$, Saint-Gobain Vetrotex International, France) having a nominal fibreglass content of $65 \mathrm{wt} \%$ in a PET matrix of 0.65 viscosity index IV (Acordis ${ }^{\circledR}$, Acordis Industrial Fibers, The Netherlands). This standard formulation of PET containing $30 \mathrm{wt} \%$ glass fibres is named R0 (no additives) here after.

This 'virgin' material reference (R0) was modified by the addition of carbon black (compounds R1, R2 and R3) and nucleating agents (compounds R2 and R3) (Table 1). The R1 formulation is filled with carbon black but contains no nucleating agent. The two other formulations contain nucleating agents. These are sodium benzoate (109494, Ciba, Germany) in case of R2 formulation and sodium 2,2'-methylenebis-(4,6-di-tert-butylphenyl)phosphate (Irgastab ${ }^{\circledR}$ NA11, Ciba, Germany) in case of R3 formulation. An oxidation inhibitor (Irganox ${ }^{\circledR} 1010$, Ciba, Germany) was also added into the matrix for all formulations. The additives (masterbatches) and concentrated glass/PET pellets were directly weighed and mixed with the neat PET material using a four com-

Table 1. Compounds formulations



${ }^{*}$ measured over the entire plate 
ponent weight blender (WSB 140, Maguire Product Inc., USA).

\subsection{Machine and mould}

The experiments were carried out on a $2000 \mathrm{kN}$ clamping force injection-moulding machine (DK Codim, France). The machine has a vertical clamping unit (injection gate located in the mould parting line), and is equipped with a $55 \mathrm{~mm}$ diameter screw specially designed for long glass fibre reinforced composites processing (Euro-Stel, Belgium).

The prototype injection mould is a rectangular plate of $300 \times 120 \times 3 \mathrm{~mm}$ (Figure 1). A $4 \mathrm{~mm}$ thick fan gate feeds the cavity over its whole width (unidirectional flow in the longitudinal direction of the plate (Figure 1b)). This mould was specially designed so as to reproduce some geometrical discontinuities (like sharp frontal and tangential steps) occurring on real industrial moulds that locally disturb the melt flow and consequently induce local micro structural heterogeneity (Figure 1a). Three pressure transducers are located at 40, 110 and $220 \mathrm{~mm}$ from the gate and are associated with two temperature sensors at 40 and $220 \mathrm{~mm}$.

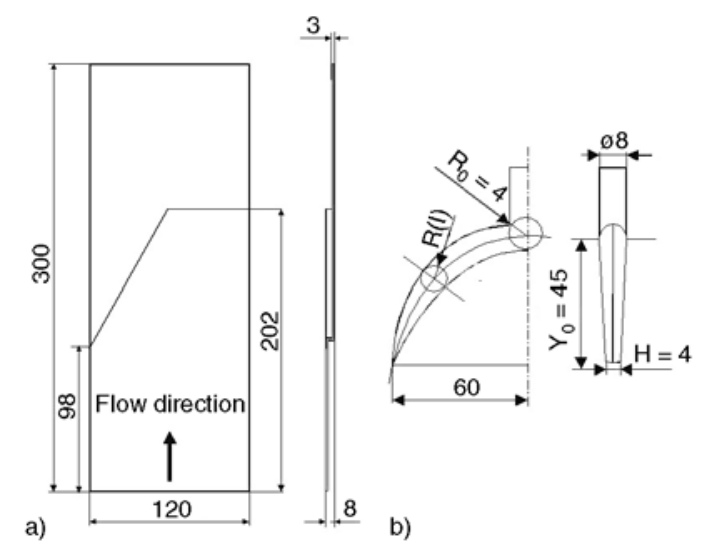

Figure 1. Plastic part (a) and gates geometries (b)

Table 2. Optimal moulding conditions from Taguchi DOE [17]

\begin{tabular}{|l|c|}
\hline \multicolumn{1}{|c|}{ Processing parameters } & Set up value \\
\hline Mould temperature $\left[{ }^{\circ} \mathrm{C}\right]$ & 150 \\
\hline Melt temperature $\left[{ }^{\circ} \mathrm{C}\right]$ & 295 \\
\hline Volumetric flow rate $\left[\mathrm{cm}^{3} \cdot \mathrm{s}^{-1}\right]$ & 178 \\
\hline Holding pressure $[\mathrm{bar}]$ & 605 \\
\hline Back pressure $[\mathrm{bar}]$ & 8 \\
\hline Screw rotation speed $[\mathrm{rpm}]$ & 40 \\
\hline Cooling time $[\mathrm{s}]$ & 20 \\
\hline
\end{tabular}

\subsection{Moulding conditions}

A Taguchi Design of Experiments (DOE) [34] was used in a previous study in order to identify the main process parameters responsible for anisotropy and heterogeneity of the moulded part, and then to optimise the injection moulding process [17]. The moulding conditions resulting from this DOE used to manufacture the parts are summarised in Table 2.

\subsection{Impact testing}

Charpy impact tests were performed in order to determine the impact strength according to ISO 179-1 or 179-2 (instrumented impact test) on a standard pendulum impact machine (Model 5101, Zwick, Germany) at $3.8 \mathrm{~mm} \cdot \mathrm{s}^{-1}$ with an 7.5 Joules impactor on ten $80 \times 10 \times 3 \mathrm{~mm}$ samples. The tests were carried out on $\mathrm{V}$-shaped notched samples (type A: notched radius $0.25 \mathrm{~mm}$, remaining width $8 \mathrm{~mm}$ ) in edgewise position and on unnotched samples in flatwise position. The test sample was cut out of the injection-moulded plates in either flow or longitudinal $(1, \mathrm{FD})$ and transverse $(2, \mathrm{TD})$ directions before (beginning section, $\mathrm{B}$ ) and after (end section, E) the step as shown in Figure 2. The impact strength was calculated according to Equation (1):

$I S=\frac{E_{\mathrm{c}}}{h \cdot b} \cdot 10^{3}$

where $I S\left[\mathrm{~kJ} \cdot \mathrm{m}^{-2}\right]$ is the impact strength, $E_{\mathrm{c}}[\mathrm{J}]$ the corrected impact energy, $h[\mathrm{~mm}]$ the sample thickness, and $b[\mathrm{~mm}]$ the sample width (unnotched test) or remaining sample width (notched test).

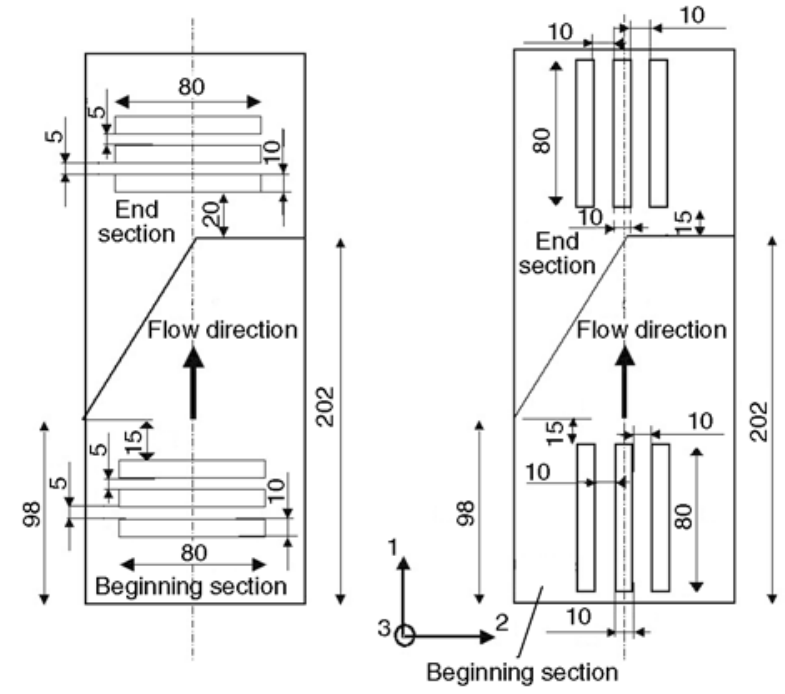

Figure 2. Location of test samples in the plate 




Figure 3. Charpy impact test configuration: Loading directions with respect to the sample multilayer structure

The loading directions of the samples are presented with respect to the induced skin/core microstructure of the samples in Figure 3. The shear and fountain flows occurring during cavity filling actually induce a well-known multilayer structure with skin layers showing a fibre orientation in the flow direction and a core layer where the fibres are oriented transversally to the flow $[10,11,24]$.

The loading mode applied during the Charpy impact test is bending. This means that the normal tensioncompression stresses applied are the highest on the sample surfaces (and equal to zero on the mid-plane). In edgewise position, all the three layers (skins and core) are subjected to the tensile or compressive loading and contribute to sustain these maximal stresses. In flatwise position, only the surface skin layers are preferentially loaded and subjected to the maximal tensile or compressive stresses. Carrying out the two types of impact test makes it therefore possible to assess relative effect of the skin.

\subsection{Fibre content measurement}

The fibre weight content was determined by ashing technique according to ASTM D 2584. The meas-



Figure 4. Cutting pattern of test samples for fibre weight content determination

urements were carried out on $25 \times 25 \mathrm{~mm}$ samples cut from three injection-moulded parts according to the cutting pattern shown in Figure 4. The average fibre weight content was also measured over the entire plate (results are reported in Table 1).

\subsection{Degree of crystallinity measurement}

The degree of crystallinity was determined on a differential scanning calorimeter (DSC7, Perkin Elmer, USA) with a heating rate of $20^{\circ} \mathrm{C} / \mathrm{min}$. A thermogravimetric analysis (TGA, Perkin Elmer, USA) was carried out in order to obtain the local matrix and fibre weight contents. The degree of crystallinity, $X_{\text {cr }}$ was calculated (Equation (2)) from the measure- 
ments of the melt enthalpy, $\Delta H_{\mathrm{F}}$ and the cold crystallisation enthalpy, $\Delta H_{\mathrm{c}}$, using the melt enthalpy of a fully crystalline poly(ethylene terephtalate), $\Delta H_{\mathrm{F} \infty}$ $(140 \mathrm{~J} / \mathrm{g})$ [35] and the matrix weight content in the sample, $m_{\mathrm{PET}}$ (Equation (2)):

$X_{\mathrm{cr}}=100 \cdot \frac{\Delta H_{\mathrm{F}}-\Delta H_{\mathrm{c}}}{\Delta H_{\mathrm{F} \infty}} \cdot \frac{m_{\mathrm{PET}}}{m}$

where $m$ is the composite weight. The measurements were carried out three times per sample at 50 and $250 \mathrm{~mm}$ from the injection gate on the plate symmetry axis.

\section{Results and discussion}

\subsection{Influence of the addition of carbon black}

Figure 5 shows that carbon black addition (R1 formulation compared to R0) significantly reduces the impact strength of the composites. The property drop is higher for notched samples (Figure 5b).

In the unnotched flatwise impact test configuration, only the skin layers sustain the mechanical loading (highest tensile-compressive normal stresses) and thus participate to the reinforcement (Figures $3 \mathrm{c}$ and $3 \mathrm{~d})$. In the case of the flow direction (FD) samples (Figure 3c), the preferential orientation of fibres in the skin layers coincides with the sample length. The impact fracture energy is not affected by carbon black addition at the beginning section (B) of the part and is only slightly lower (15\%) at the end section (E) of the part (Figure 5a). In that case, this is the aligned fibres that are loaded principally; the impact behaviour modification due to the addition of carbon black into the matrix is thus limited. In the case of transverse (TD) samples, the skin layers supporting the highest normal stresses have aligned fibres preferentially oriented through the sample width (Figure 3d). The strength decrease is much

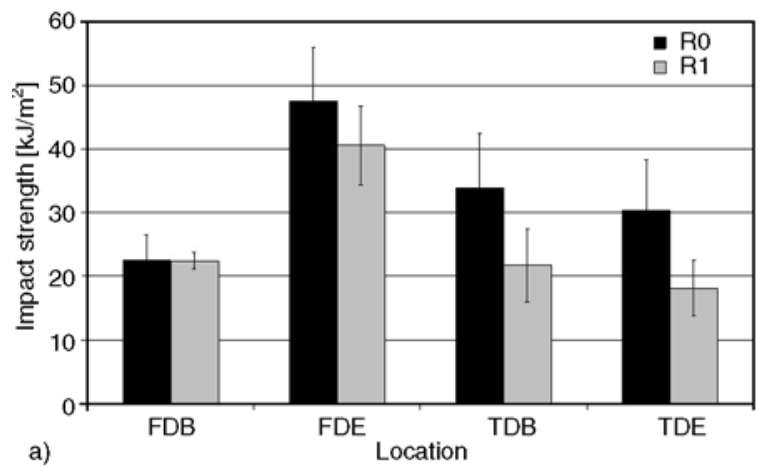

more noticeable and reaches more than $35 \%$ wherever the measurement location is. In that case, it is the matrix that is principally loaded. Its modification by carbon black addition therefore significantly influences the impact behaviour accordingly.

In the notched edgewise impact test configuration, the entire multi-layered structure of the composite is subjected to mechanical loading; all the layers, i.e. both the skin and core layers, contribute to sustain the highest normal stresses and thus contribute to the impact resistance (Figures $3 a$ and $3 b$ ). As a consequence, whatever the sample direction may be, there is at least one layer (either skin or core) for which the preferential fibre alignment does not match the normal stresses principal direction, that is to say for which the matrix is principally loaded. Thus, the addition of carbon black always induces a significant strength decrease. This decrease is about $50 \%$ for flow direction (FD) samples, and about $35 \%$ for transverse direction (TD) samples. As there is a fibre accumulation in the core layer due to fibre segregation phenomena reported previously [11, 17], the effect of the matrix brittleness is higher for the flow direction samples (most of the fibres are aligned in the impact direction (Figure 3a)).

Recording the force/displacement curves provides data related to damage initiation and growth. In the unnoched flatwise impact test configuration, the energy dissipated during the fracture (area under the curve) are 1.3 times higher for the virgin formulation (R0) than for the black formulation (R1) in the transverse direction (Figure 6). It is however mainly the crack growth energy that differentiates both formulations. In the notched edgewise impact test configuration, in the flow direction where the carbon black induced weakening is the highest, the composites moulded with the black coloured com-



Figure 5. Unnotched flatwise (a) and notched edgewise (b) Charpy impact strengths in flow (FD) and transverse directions (TD) at beginning (B) and end (E) of the part - Effect of carbon black (R1) compared to virgin (R0) PET/30 wt\% LGF 
pound (R1) clearly resist less to crack growth (Figure 7); breakage rapidly occurs after crack initiation.

Carbon black influences the matrix crystallization, its particles forming nucleating sites [30] as glass fibres do. The measurement of the degree of crystallinity at the conventional locations (beginning and end sections of the part) indicates a homogenisation of the microstructure of the carbon black coloured part (R1) compared to the virgin one (R0). This noticeable effect has to be linked to the impor-

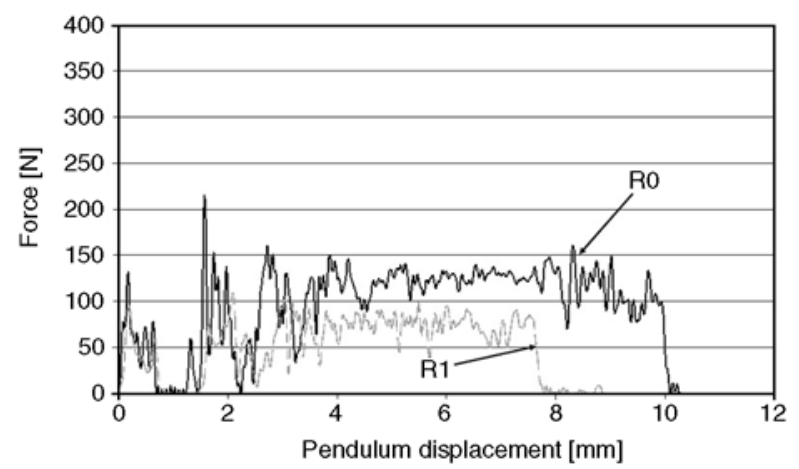

Figure 6. Force/displacement curve recorded during unnotched flatwise Charpy impact test in transverse direction at the beginning of the part Effect of carbon black (R1) compared to virgin (R0) PET/30 wt $\%$ LGF

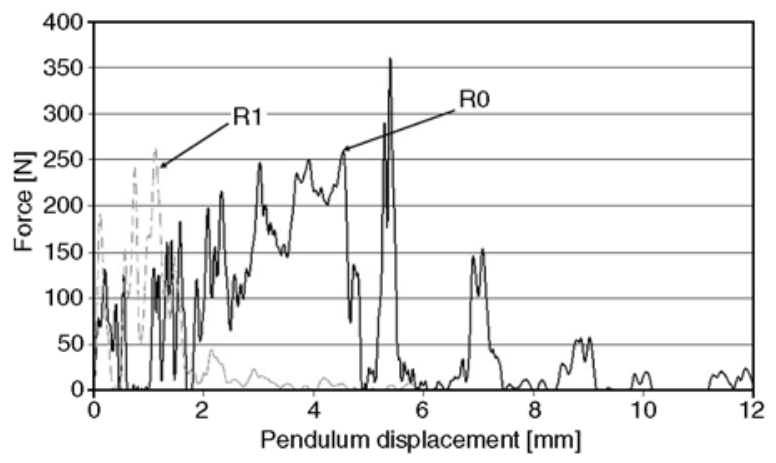

Figure 7. Force/displacement curve recorded during notched edgewise Charpy impact test in flow direction at the beginning of the part - Effect of carbon black (R1) compared to virgin (R0) PET/30 wt\% LGF tant fibre content decrease at the end of the plate (Table 3), fibres acting themselves as nucleating sites. The local fibre content is $8 \mathrm{wt} \%$ lower compared the virgin (R0) formulation may partly explain the impact strength drop at this location. Nonetheless, at the beginning of the part where fibre content and degree of crystallinity are similar, the notched impact strengths are still lower for the black coloured parts (R1).

Processing related data may explain the abovementioned reduction of fibre segregation effect. Lower filling time $(0.2 \mathrm{~s}$ measured in front of each pressure sensors) was recorded for the black coloured compound R1, that is to say lower pressure loss, suggesting higher fluidity. As a direct consequence, this viscosity diminution decreases the shear stresses in the melt flow and thus the previously noticed $[11,17]$ fibre segregation occurring during cavity filling. Thanks to its good thermal conductivity, carbon black induces a quicker cooling of the polymer in the cavity (Figure 8), thus shorter freezing times that decrease the holding phase efficiency. Carbon black seems therefore to act not only as a thermal transfer activator but also as a mechanical fluidization agent (lubricating agent) in the same way as talc or glass beads.

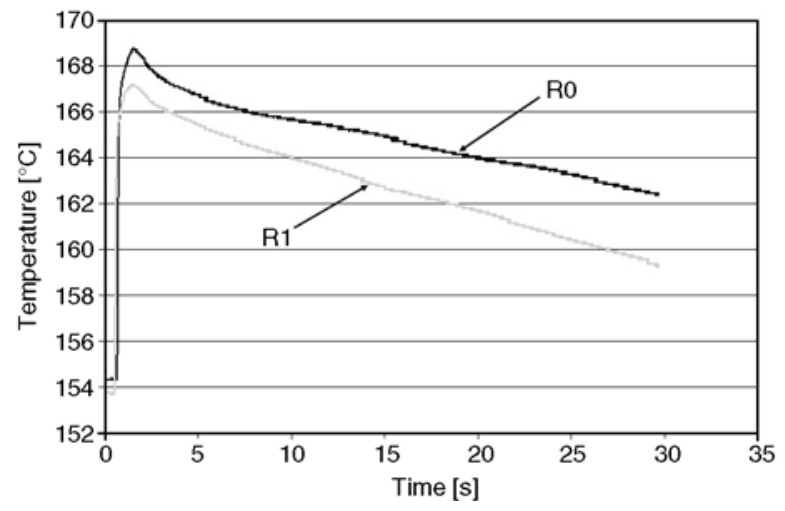

Figure 8. Part temperature during cooling in the mould at $40 \mathrm{~mm}$ from the gate - Effect of carbon black (R1) compared to virgin (R0) PET/30 wt\% LGF

Table 3. Influence of nucleating agents, carbon black and mould temperature on the part microstructure

\begin{tabular}{|c|c|c|c|c|c|c|c|c|c|}
\hline \multirow{2}{*}{$\begin{array}{l}\text { PET } / 30 \text { wt } \% \text { LGF } \\
\text { reference }\end{array}$} & \multirow{2}{*}{$\begin{array}{c}\text { Mould temperature } \\
{\left[{ }^{\circ} \mathrm{C}\right]}\end{array}$} & \multicolumn{4}{|c|}{ Fibre content [wt\%] } & \multicolumn{4}{|c|}{ Degree of crystallinity $X_{\mathrm{cr}}[\%]$} \\
\hline & & Beginning & SD $^{*}$ & End & SD $^{*}$ & Beginning & SD $^{*}$ & End & SD \\
\hline R0 & 150 & 30.6 & 0.8 & 38.2 & 2.6 & 30.9 & 4.6 & 39.1 & 1.8 \\
\hline R1 & 150 & 28.9 & 7.2 & 30.3 & 2.4 & 28.3 & 4.1 & 28.9 & 4.3 \\
\hline $\mathrm{R} 2$ & 150 & 29.5 & 6.0 & 33.1 & 0.4 & 36.8 & 1.8 & 36.1 & 2.0 \\
\hline R3 & 150 & 31.4 & 5.0 & 30.6 & 1.8 & 31.6 & 2.0 & 31.9 & 1.9 \\
\hline $\mathrm{R} 2$ & 140 & 28.7 & 5.6 & 33.9 & 1.1 & 32.3 & 2.2 & 30.7 & 3.3 \\
\hline R3 & 140 & 36.0 & 1.7 & 39.6 & 1.5 & 33.7 & 2.0 & 33.7 & 2.7 \\
\hline
\end{tabular}

${ }^{*}$ SD: Standard deviation 
Besides, carbon black also acts as filler. It reduces the matrix ductility [36] and creates brittleness sites that participate to the composite fracture at low stress levels. The impact brittleness then depends on both the filler content and size [36, 37]. The fracture surfaces of the carbon black coloured material (R1) indicate a good fibre/matrix adhesion with limited fibre pull-out and debonding (Figures 9a and $9 b)$. The matrix does not show any polymer strips to
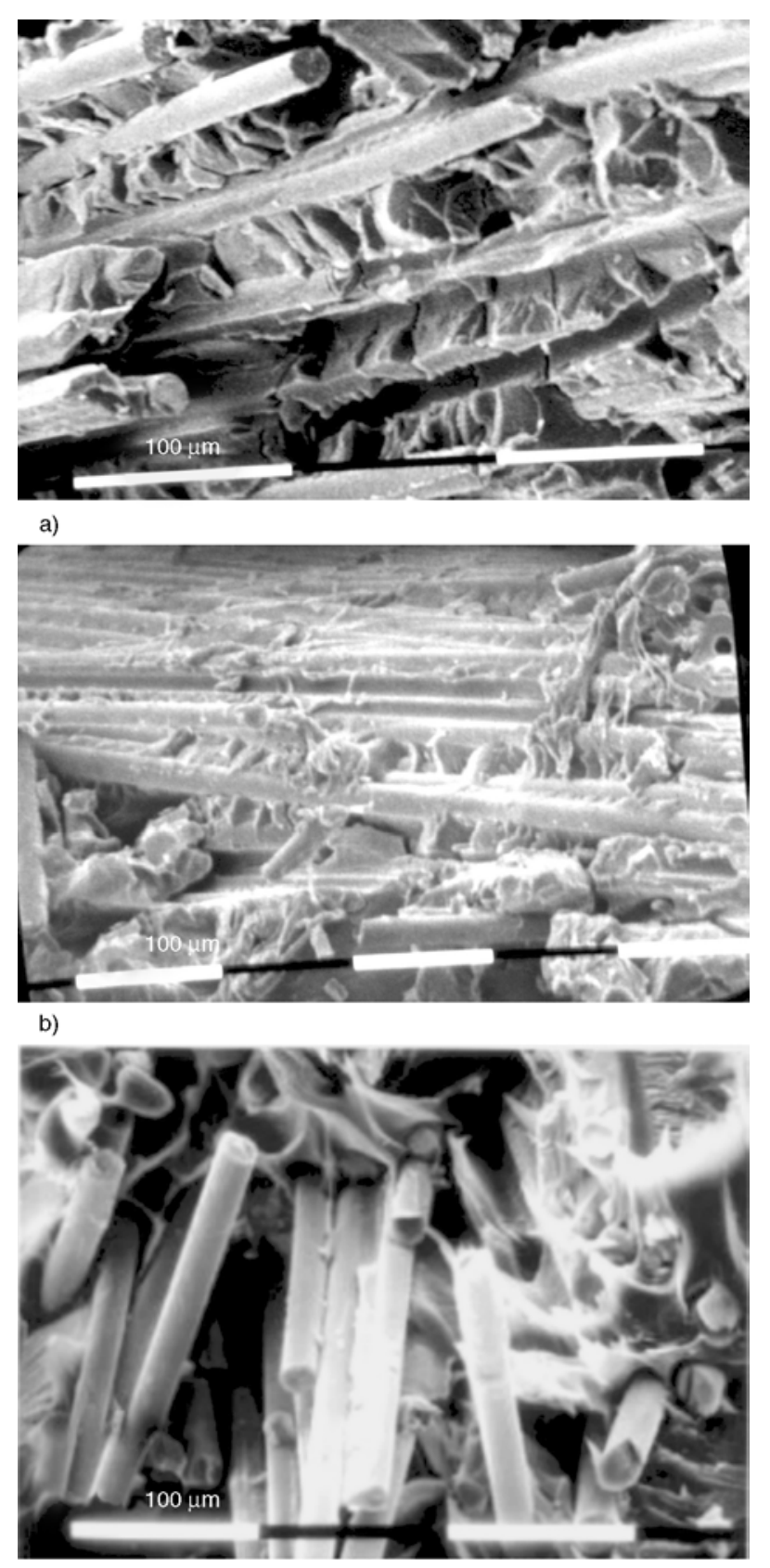

c)

Figure 9. Fracture surfaces after notched edgewise (a, c) or unnotched flatwise (b) Charpy impact test at plate beginning for R1 $(a, b)$ and R0 (c) formulation be related to plastic deformation but many cracks normal to the fibres (Figure 9a) probably originating from stress concentrations around them. The fracture surface of the virgin material (R0) is fully different (Figure 9c) showing smooth fibres and fibre pull-out, signs of poor fibre/matrix adhesion.

The better fibre/matrix adhesion observed for R1 (compared to R0) may be ascribed to the so-called 'frettage' stresses (shrink-fitting or coiling effect), induced by the shrinkage of the matrix around the fibres and already explained elsewhere [17, 38]. This fibre 'frettage' effect depends on the cooling rate of the part (higher for R1 than for R0 as mentioned above). The latter also governs the stress relaxation ability of the material. At high cooling rate, the internal frettage stresses are frozen, cannot relax easily; the matrix is therefore pre-loaded and is much more sensitive to microcracking around the fibres when further mechanically loaded. The good interfacial adhesion is responsible for the low impact strength of the carbon black coloured material (R1), owing to the fact that its ability to dissipate the impact energy by fibre/matrix debonding and fibre pull-out is poor. The impact strength also depends on matrix ductility as well as on the amplitude of the frettage stresses around the fibres: The higher the matrix ductility and the lower the internal frettage stresses, the higher the impact strength of the material (case of R0 formulation).

\subsection{Influence of the addition of nucleating agents}

From an industrial standpoint, nucleating agents are often used to promote a quicker crystallization of the injection-moulded parts (modification of the crystallization kinetics of the matrix) in order to reduce cycle times or mould temperature. They are also likely to modify the (transcrystalline) interphase structure [36]. Knowing that the very first damage step of long fibre reinforced thermoplastics is fibre/matrix debonding [4], the impact behaviour may be consequently affected by nucleating agent addition. It is therefore worth assessing the influence on the impact properties of the addition of nucleating agents on the one hand, of their chemical nature on the other hand, and finally of the mould temperature (which governs the parts cooling rate). 


\subsubsection{Effect of nucleating agents}

Consequently, this section is first going to focus on the three black coloured formulations (R1, R2, R3) injection-moulded in the standard conditions (mould temperature at $150^{\circ} \mathrm{C}$, Table 2) in order to investigate the influence of different types of nucleating agents. Adding a nucleating agent such as sodium benzoate (R2) to the carbon black coloured compound allows improving its impact strength whatever the test configuration may be.

The chemical nature of the nucleating agent (sodium benzoate R2 or sodium 2,2'-methtylene-bis(4,6-ditert-butylphenyl)phosphate R3) particularly influences the unnotched flatwise impact strength. The best mechanical performance is achieved with the sodium benzoate based (R2) formulation as shown in Figure 10a. The impact strength reached with this additive is always higher than that measured for the $\mathrm{R} 1$ formulation, which is not the case with the sodium phosphate nucleating agent (R3). In the notched edgewise impact test configuration, the addition of a nucleating agent (R2 or R3) improves the impact strength of the material (compared to $\mathrm{R} 1), \mathrm{R} 2$ being more efficient than R3. In this test configuration, where the entire multi-layered composite structure is submitted to mechanical loading and participates to sustain the applied maximum normal stresses, the chemical nature of the nucleating agent (R2 or R3) has only a limited effect on the impact strength in flow direction. A significant impact strength improvement is however noticed for the sodium benzoate based formulation (R2) in the transverse direction $(+30 \%$ on average between the two formulations) (Figure 10b). Such a better efficiency of sodium benzoate (R2) compared to phosphate based (R3) nucleating agent may be surpris-

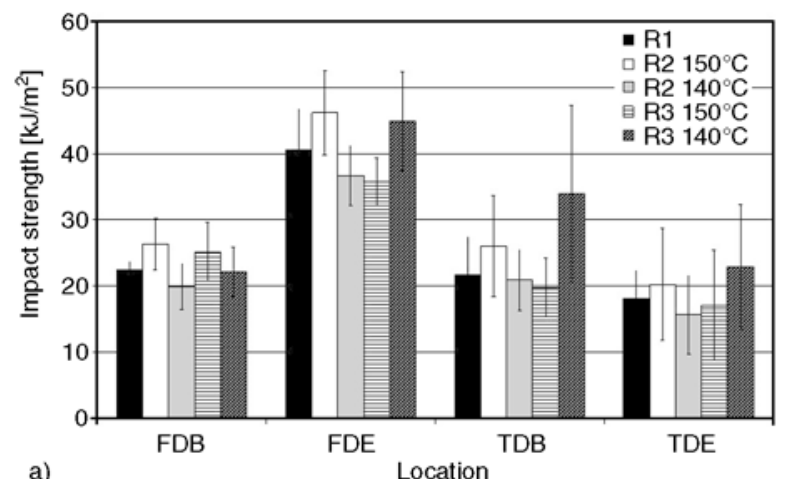

ing. Indeed, according to the literature, sodium 2,2'methtylene-bis(4,6-di-tert-butylphenyl)phosphate

(R3) is likely to induce smaller spherulites than sodium benzoate (R2) in non-reinforced plastics $[28,29]$. However, in the case of fibre-reinforced plastics, a more perfect crystalline structure (small spherulite sizes, homogeneous spherulite structure, possibly transcrystalline interphase - as expected in the case of R3) increases the internal stresses in the fibre/matrix interface region and therefore the material brittleness [10]. These stresses concentrated around the fibres are easily revealed by means of a soda-ethanol chemical attack which induces material cracking due to stress relaxation (Figure 11).

Compared to the carbon black coloured formulation (R1), nucleating agents logically increase the crystallinity of the composites (Table 3 ). When the parts are moulded in the standard conditions (mould temperature at $150^{\circ} \mathrm{C}$, Table 2), the local fibre contents are roughly similar whatever the additive may be. However, the PET matrix crystallizes much more

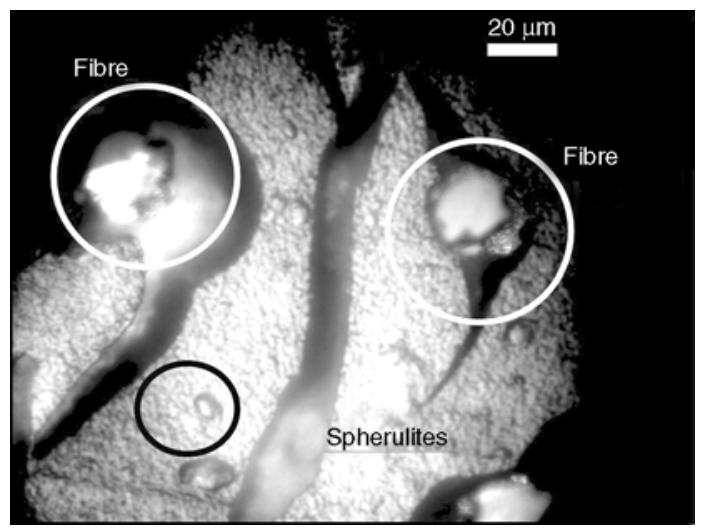

Figure 11. Fracture surface after chemical soda-ethanol attack for R3 formulation moulded at $150^{\circ} \mathrm{C}-$ Internal stresses at fibre/matrix interface

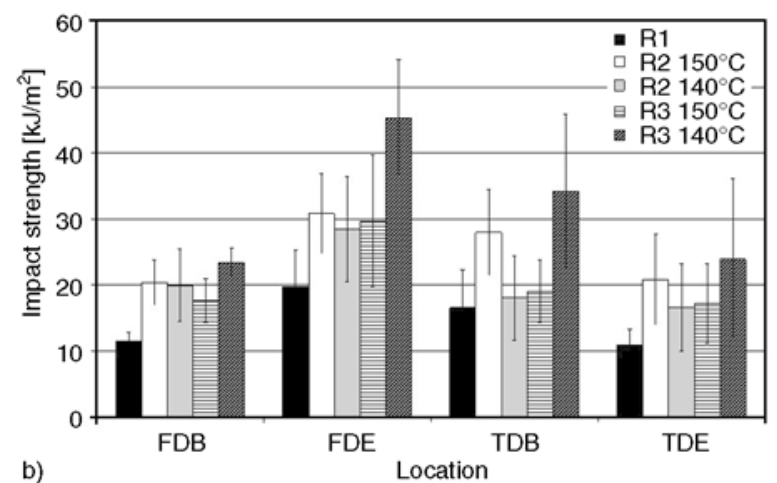

b)

Figure 10. Unnotched flatwise (a) and notched edgewise (b) Charpy impact strengths in flow (FD) and transverse directions (TD) at beginning (B) and end (E) of the part - Effect of nucleating agent type (R2, R3) and mould temperature compared to black coloured (R1) PET/30 wt $\%$ LGF 
easily when sodium benzoate (R2) is added as a nucleating agent. Compared to the additive-free reference material (R0), which is characterised by important microstructure variations between the beginning and the end of the plate, the parts are more homogeneous in terms of both fibre contents and degrees of crystallinity Apart from the previously mentioned fluidisation effect of carbon black, such a limitation of the fibre segregation phenomenon may be also ascribed to another effect. In the case of the nucleating agent containing formulations (R2 and R3), the fibres or portions of fibres frozen in the solid layer during cavity filling may be more numerous due to the quicker crystallization kinetics induced by nucleating agents (the feeding of the molten layer with broken or pulled-out fibres being less in that case).

\subsubsection{Influence of mould temperature}

A decrease of the mould temperature (from 150 to $140^{\circ} \mathrm{C}$ ) generally allows getting better impact properties when using sodium 2,2'-methtylene-bis(4,6di-tert-butylphenyl)phosphate nucleating agent (R3), if one excepts the peculiar behaviour of the FBD sample in the unnotched test configuration for which no relevant explanation was found here. The impact strength globally reaches the same values as those of the additive-free reference material (R0) moulded at $150^{\circ} \mathrm{C}$ (Figure 5), and is higher than (or if not at least almost equivalent to) that of the other carbon black coloured materials (R1, R2) moulded at $150^{\circ} \mathrm{C}$ (Figure 10). In contrary, the formulation based on sodium benzoate (R2) shows a clear property loss when moulded at lower temperature.

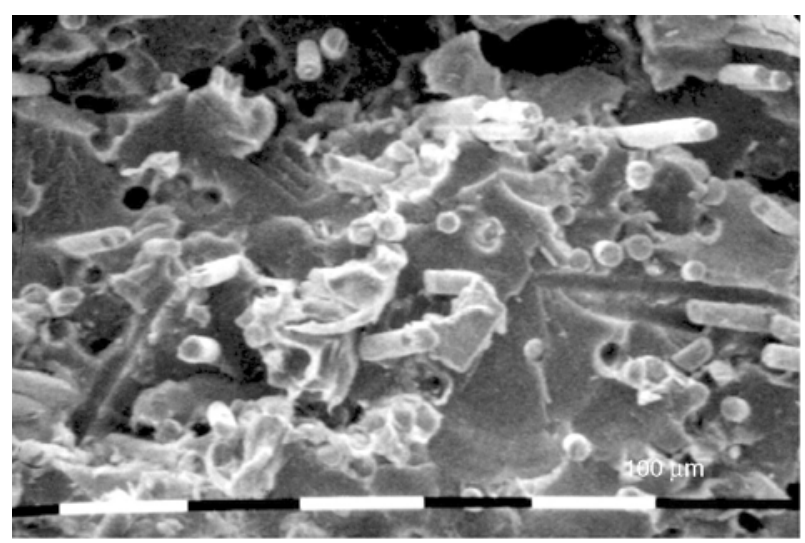

a)
The change of mould temperature can induce modifications of flow mechanisms, and consequently of the composite microstructure. In the case of sodium benzoate based formulation (R2), there is no change of fibre content distribution within the part; however a noticeable decrease of the degree of crystallinity is observed (Table 3 ). In the case of sodium 2,2'-methtylene-bis(4,6-di-tert-butylphenyl) phosphate based formulation (R3), a longitudinal fibre segregation similar to the one already observed with the additive-free reference material (R0) is noticed with fibre accumulations at the end of the part, the degree of crystallinity remaining roughly the same whatever the mould temperature is.

The fracture behaviour also changes with the mould temperature. Hence, the fracture of the sodium phosphate based formulation (R3) is brittle at a mould temperature of $150^{\circ} \mathrm{C}$ (Figure 12a), whereas an important plastic deformation and breakage of fibres are observed at a mould temperature of $140^{\circ} \mathrm{C}$ (Figure 12b). The plastic strain observed for the sodium phosphate based formulation (R3) at

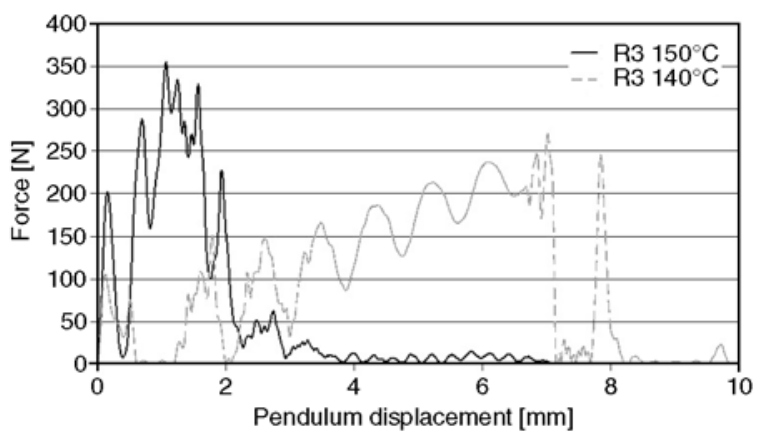

Figure 13. Force/displacement curve recorded during notched edgewise Charpy impact test in flow direction at the end of the part - Effect of moulding temperature for R3 formulation

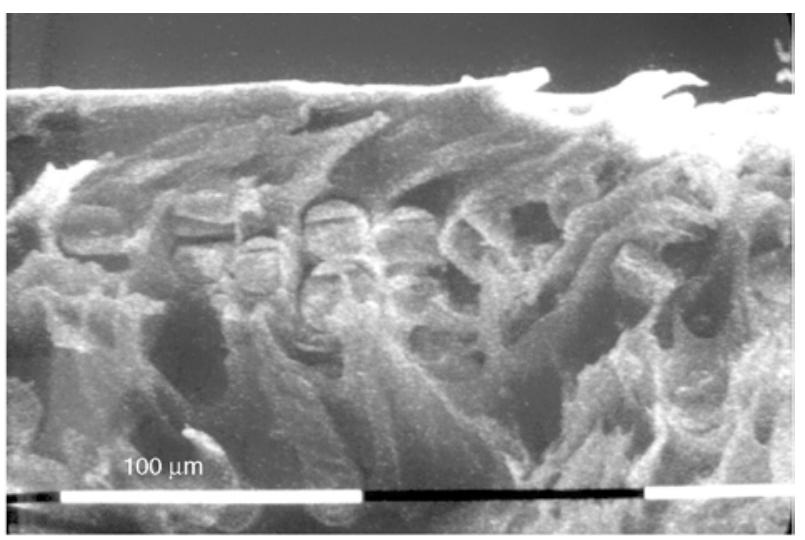

b)

Figure 12. Fracture surfaces after unnotched flatwise Charpy impact test for R3 formulation - Effect of mould temperature (a) $150^{\circ} \mathrm{C}$ (b) $140^{\circ} \mathrm{C}$ 


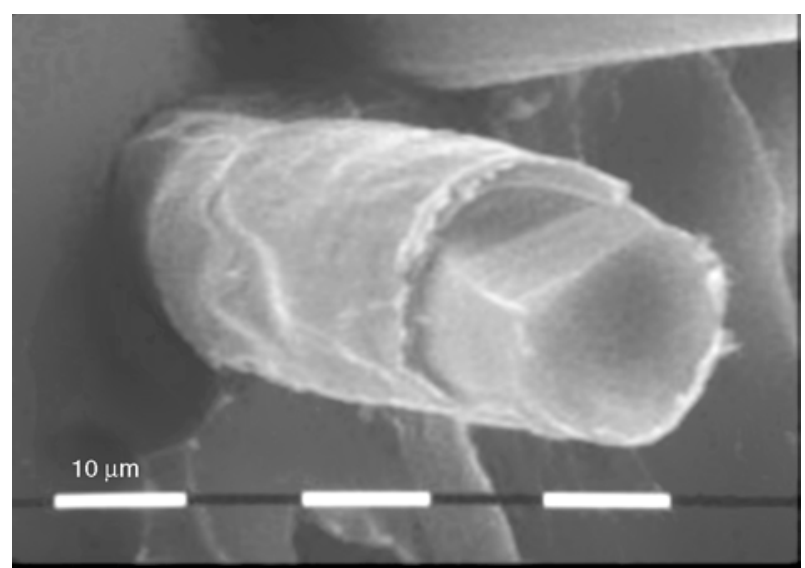

Figure 14. Fracture surface after notched edgewise Charpy impact test at plate beginning for R3 formulations moulded at $150^{\circ} \mathrm{C}$ - Transcrystalline structure

$140^{\circ} \mathrm{C}$ may explain the impact strength strong increase whatever the test configuration is. It results in a ductility increase as shown on the force/displacement curves (Figure 13). This may be ascribed to a modification of the crystalline area between the fibres and the matrix (as defined by Vu-Khanh and Denault [20]), and especially the formation of a transcrystalline zone. Such a transcrystalline layer was evidenced for the R3 formulation only (Figure 14). For this reference only, a significant increase of the cooling rate was evidenced by the drop of internal pressure within the mould during the holding stage of the injection-moulding cycle.

\section{Conclusions}

The presence of additives in the polymer matrix (pigments/dyes, nucleating agents) induces microtructure modification of long glass fibre reinforced PET composites that in turn causes variations in impact performances.

When carbon black is used as the only additive for a black colouring purpose, it generates an impact property loss whatever the loading mode is (unnotched flatwise impact or notched edgewise impact). A mechanical fluidisation during the filling stage of the mould modifies the local fibre content and thus is likely to influence fibre orientation, forming a more isotropic and homogeneous part. Due to its thermal conductivity, this additive increases the cooling rate of the part, thus decreasing the degree of crystallinity. However, it also acts as filler that significantly weakens the composite during impact loading.
The nucleating agents allow reducing mould temperatures, thus also cycle times by increasing the cooling rates. However their effect on impact strengths may be favourable or detrimental depending on their chemical nature and the processing temperatures. Moreover their effect is possibly hindered by the simultaneous addition of carbon black, which is very common in automotive applications. Adding carbon black or nucleating agents into the polymer matrix of PET long fibre thermoplastics induces perturbation of both the rheology of the melt flow in the cavity and the cooling kinetic of the parts that act together on the fibre distribution during the filling stage and on the composite degrees of crystallinity. The mechanical performances are consequently highly affected.

\section{Acknowledgements}

Thanks are due to the European Union (FEDER, European Funds for Regional Development) for contributing to the funding of equipment.

\section{References}

[1] Markarian J.: Automotive composites. Plastics Engineering, 67, 22-29 (2011).

[2] Monteil J-B.: European automotive industry's demand for reinforced plastics on the rise. JEC Composites Magazine, 28, 24-25 (2006).

[3] Thomason J. L., Vlug M. A.: Influence of fibre length and concentration on the properties of glass fibre-reinforced polypropylene: 1 . Tensile and flexural modulus. Composites Part A: Applied Science and Manufacturing, 27, 477-484 (1996). DOI: 10.1016/1359-835X(95)00065-A

[4] Thomason J. L., Groenewoud W. M.: The influence of fibre length and concentration on the properties of glass fibre reinforced polypropylene: 2 . Thermal properties. Composites Part A: Applied Science and Manufacturing, 27, 555-565 (1996).

DOI: $10.1016 / 1359-835 X(96) 00016-4$

[5] Thomason J. L., Vlug M. A., Schipper G., Krikor H. G. L. T.: Influence of fibre length and concentration on the properties of glass fibre-reinforced polypropylene: Part 3. Strength and strain at failure. Composites Part A: Applied Science and Manufacturing, 27, 10751084 (1996).

DOI: $10.1016 / 1359-835 X(96) 00066-8$

[6] Thomason J. L., Vlug M. A.: Influence of fibre length and concentration on the properties of glass fibre-reinforced polypropylene: 4. Impact properties. Composites Part A: Applied Science and Manufacturing, 28, 277288 (1997).

DOI: $\underline{10.1016 / \mathrm{S} 1359-835 \mathrm{X}(96) 00127-3}$ 
[7] Thomason J. L.: The influence of fibre length and concentration on the properties of glass fibre reinforced polypropylene: 5. Injection moulded long and short fibre PP. Composites Part A: Applied Science and Manufacturing, 33, 1641-1652 (2002).

DOI: $10.1016 / \mathrm{S} 1359-835 \mathrm{X}(02) 00179-3$

[8] Thomason J. L.: The influence of fibre length and concentration on the properties of glass fibre reinforced polypropylene. 6 . The properties of injection moulded long fibre PP at high fibre content. Composites Part A: Applied Science and Manufacturing, 36, 995-1003 (2005).

DOI: 10.1016/j.compositesa.2004.11.004

[9] Thomason J. L.: The influence of fibre length and concentration on the properties of glass fibre reinforced polypropylene: 7 . Interface strength and fibre strain in injection moulded long fibre PP at high fibre content. Composites Part A: Applied Science and Manufacturing, 38, 210-216 (2007).

DOI: $10.1016 /$ j.compositesa.2006.01.007

[10] Lafranche E., Krawczak P., Ciolczyk J. P., Maugey J.: Injection moulding of long glass fibre reinforced polyamide 6-6: Guidelines to improve flexural properties. Express Polymer Letters, 1, 456-466 (2007). DOI: 10.3144/expresspolymlett.2007.64

[11] Lafranche E., Krawczak P., Ciolczyk J-P., Maugey P.: Injection moulding of long glass fiber reinforced polyamide 66: Processing conditions/microstructure/flexural properties relationship. Advances in Polymer Technology, 24, 114-131 (2005).

DOI: $10.1002 / \mathrm{adv} .20035$

[12] Thomason J. L.: The influence of fibre length, diameter and concentration on the strength and strain to failure of glass fibre-reinforced polyamide 6,6. Composites Part A: Applied Science and Manufacturing, 39, 16181624 (2008).

DOI: $10.1016 /$ j.compositesa.2008.07.002

[13] Thomason J. L.: The influence of fibre length, diameter and concentration on the modulus of glass fibre reinforced polyamide 6,6. Composites Part A: Applied Science and Manufacturing, 39, 1732-1738 (2008). DOI: 10.1016/j.compositesa.2008.08.001

[14] Thomason J. L.: The influence of fibre properties on the properties of glass-fibre-reinforced polyamide 6,6 . Journal of Composite Materials, 34, 158-172 (2000). DOI: $10.1177 / 002199830003400205$

[15] Thomason J. L.: Micromechanical parameters from macromechanical measurements on glass reinforced polyamide 6,6. Composite Science and Technology, 61, 2007-2016 (2001).

DOI: $10.1016 / \mathrm{S} 0266-3538(01) 00062-8$

[16] Thomason J. L: The influence of fibre length, diameter and concentration on the impact performance of long glass-fibre reinforced polyamide 6,6. Composites Part A, 40, 114-124 (2009).

DOI: $10.1016 /$ j.compositesa.2008.10.013
[17] Cilleruelo L., Lafranche E., Krawczak P., Pardo P., Lucas P.: Injection moulding of long-glass-fibre-reinforced poly(ethylene terephthalate): Influence of processing conditions on flexural and impact strengths. Polymers and Polymer Composites, 16, 577-588 (2008).

[18] Karger-Kocsis J., Harmia T., Czigány T.: Comparison of the fracture and failure behavior of polypropylene composites reinforced by long glass fibers and by glass mats. Composites Science and Technology, 54, 287298 (1995).

DOI: 10.1016/0266-3538(95)00068-2

[19] Karger-Kocsis J.: Instrumented impact fracture and related failure behavior in short- and long-glass-fiberreinforced polypropylene. Composites Science and Technology, 48, 273-283 (1993).

DOI: 10.1016/0266-3538(93)90144-6

[20] Vu-Khanh T., Denault J.: Fracture behaviour of long fibre reinforced thermoplastics. Journal of Materials Science, 29, 5732-5738 (1994).

DOI: $10.1007 / \mathrm{BF} 00349973$

[21] Bartus S. D., Vaidya U. K.: Performance of long fiber reinforced thermoplastics subjected to transverse intermediate velocity blunt object impact. Composite Structures, 67, 263-277 (2005).

DOI: $10.1016 /$ j.compstruct.2004.07.023

[22] Skourlis T. P., Mehta S. R., Chassapis C., Manoochehri S.: Impact fracture behavior of injection molded long glass fiber reinforced polypropylene. Polymer Engineering and Science, 38, 79-89 (1998).

DOI: $10.1002 /$ pen.10167

[23] Mucha M., Marszalek J., Firdych A.: Crystallization of isotactic polypropylene containing carbon black as a filler. Polymer, 41, 4137-4142 (2000).

DOI: $10.1016 / \mathrm{S} 0032-3861(99) 00706-5$

[24] Dekoninck J. M., Legras R., Mercier J. P.: Nucleation of poly(ethylene terephthalate) by sodium compounds: A unique mechanism. Polymer, 30, 910-913 (1989). DOI: 10.1016/0032-3861(89)90191-2

[25] Garcia D.: Heterogeneous nucleation of poly(ethylene terephthalate). Journal of Polymer Science: Polymer Physics Edition, 22, 2063-2072 (1984). DOI: $10.1002 /$ pol.1984.180221206

[26] Ye M., Wang X., Huang W., Hu J., Bu H.: Fast crystallization of poly(ethylene terephthalate). Journal of Thermal Analysis and Calorimetry, 46, 905-920 (1996). DOI: 10.1007/BF01983610

[27] Jiang X. L., Luo S. J., Sun K., Chen X. D.: Effect of nucleating agents on crystallization kinetics of PET. Express Polymer Letters, 1, 245-251 (2007). DOI: 10.3144 /expresspolymlett.2007.37

[28] Botkin J. H., Dunski N., Maeder D.: Improving molding productivity and enhancing mechanical properties of polypropylene with nucleating agents. in 'SPE Automotive TPO Global Conference 2002 Conference Proceedings, Dearborn, USA' 163-170 (2002). 
[29] Zhang Y-F., Xin Z.: Effects of substituted aromatic heterocyclic phosphate salts on properties, crystallization, and melting behaviors of isotactic polypropylene. Journal of Applied Polymer Science, 100, 4868-4874 (2006).

DOI: 10.1002/app.23209

[30] Pompe G., Mäder E.: Experimental detection of a transcrystalline interphase in glass-fibre/polypropylene composites. Composites Science and Technology, 60, 2159-2167 (2000).

DOI: $10.1016 / \mathrm{S} 0266-3538(00) 00120-2$

[31] Zhang X., Xie F., Pen Z., Zhang Y., Zhang Y., Zhou W.: Effect of nucleating agent on the structure and properties of polypropylene/poly(ethylene-octene) blends. European Polymer Journal, 38, 1-6 (2002). DOI: 10.1016/S0014-3057(01)00182-3

[32] Salazar A., Rico A., Rodrígez S., Navarro J. M., Rodrígez J.: Relating fracture behavior to spherulite size in conrolled-rheology polypropylene. Polymer Engineering and Science, 52, 805-813 (2011). DOI: $10.1002 /$ pen. 22145
[33] Xu T., Yu J., Jin Z.: Effects of crystalline morphology on the impact behavior of polypropylene. Materials and Design, 22, 27-31 (2001).

DOI: $10.1016 / \mathrm{S} 0261-3069(00) 00033-9$

[34] Taguchi G., Konishi S., Wu Y.: Taguchi methods: Research and development. Quality Engineering Series, Vol. 1. ASI Press, Dearborn (1992).

[35] Arnoult M., Dargent E., Mano J. F.: Mobile amorphous phase fragility in semi-crystalline polymers: Comparison of PET and PLLA. Polymer, 48, 1012-1019 (2007). DOI: $10.1016 /$ j.polymer.2006.12.053

[36] Unal H.: Morphology and mechanical properties of composites based on polyamide 6 and mineral additives. Materials and Design, 25, 483-487 (2004). DOI: $10.1016 / \mathrm{j}$. matdes.2004.01.007

[37] Mareri P., Bastide S., Binda N., Crespy A.: Mechanical behaviour of polypropylene composites containing fine mineral filler: Effect of filler surface treatment. Composites Science and Technology, 58, 747-752 (1998). DOI: $10.1016 / \mathrm{S} 0266-3538(97) 00156-5$

[38] Tancrez J. P.: Study of the brittleness of injection moulded short-glass-fibre-reinforced polypropylene matrix composites (in French). PhD Thesis, University of Lille I - Ecole des Mines de Douai (1994). 